\title{
Statistical analysis of night radiance RH using VIIRS day/night band satellite time series data
}

\author{
Jyoti U. Devkota \\ Department of Natural Sciences (Statistics), Kathmandu University, Nepal
}

\begin{tabular}{l}
\hline \hline Article Info \\
\hline Article history: \\
Received Jan 11, 2019 \\
Revised Jan 22, 2019 \\
Accepted Apr 12, 2019 \\
\hline
\end{tabular}

\section{Keywords:}

Statistical analysis Boxplot

Linear regression

VIIRS satellite DNB data

\begin{abstract}
Amount of night lights in an area is a proxy indicator of electricity consumption. This is interlinked to indicators of economic growth such as socio-economic activities, urban population size, physical capital, incidence of poverty. These night lights are generated by renewable and non renewable energy source. In this paper the behavior of night radiance RH data was minutely analyzed over a period of 28 hour; Visible Infrared Imaging Radiometer Suite Day/Night Band (VIIRS DNB) satellite earth observation data were used. These 28 hours and 8936 observations time series data is from 2 September 2018 to 4 September 2018. The behavior of night radiance RH data over 122 time intervals was analyzed using box plots. It was seen that the arithmetic mean of $\mathrm{RH}$ data is more sensitive than the arithmetic mean of first order difference of RH data. The first order difference of night radiance $\mathrm{RH}$ was regressed on night radiance over 110 intervals of time. The box plot of slope and intercept of this linear regression showed the behavior of these regression parameters over 110 intervals of time. It is seen that the data are more scattered with respect to slope than with respect to intercept. This implies that the rate of change in $\mathrm{RH}$ with respect to change in time has more variability that the intrinsic value of RH data at the sampled point of time.
\end{abstract}

Copyright $\odot 2019$ Institute of Advanced Engineering and Science. All rights reserved.

\section{Corresponding Author:}

Jyoti U. Devkota

Mathematical Science Group, Department of Natural Science, School of Science,

Kathmandu University,

P.O. Box 9303, Kathmandu, Nepal.

Email:drjdevkota@ku.edu.np, devkotajb@gmail.com

\section{INTRODUCTION}

Renewable and non renewable energies are sources to night time lights. These night lights illuminate bridges, streets, ship fleets, buildings etc. The data on night lights can be obtained from earth observation data of satellites. Researchers have found a positive correlation between night time light data and several socio-economic variables [1]. The free and inexpensive satellite time series data on night lights can thus be used for in-depth statistical analysis with vast interdisciplinary applications.

This night time light provides lighting in darkness. This night radiance is also an indicator of socio economic activities conducted in the night. As most of socioeconomic activities at night require light, the intensity of night time lights and the area covered by it correlate with socioeconomic activities and economic development. The brightness of indoor and outdoor night time light can be seen from the space due to satellite imagery. In areas lacking with data on economic accounting, night time satellite data can give us an estimate of economic growth. All vital inputs needed for survival and economic development of a society are provided by energy. Energy used in night time activity plays a very important role in this dynamics.

Changes in population density can also be analysed using data on night time lights. Power outages in urban areas can also be spotted through these data. These power blackouts could be due to disasters and 
natural calamities. Increase in night time radiance implies population growth, economic growth and improved living standards.

This paper is based on data products from the Visible Infrared Imaging Radiometer Suite (VIIRS) night time sensors. They are also called Day/Night Band, or DNB. Elvidge, Zhinzhin, Hsu and Baugh discussed satellite pyrometry at night and also gave background information about these VIIRS data [2]. Koel and Simon modelled crude birth rate and maternal mortality ratio of India using night time satellite images [3]. Mann, Melaas and Mallick used VIIRS/DNB to measure electricity supply reliability in Maharastra India [4]. Yu et al. claim that VIIRS data is a useful tool for evaluating poverty at county level in China [5]. Sharma et al. combined Moderate Resolution Imaging Spectroradiometer (MODIS)-based multispectral data with the Visible Infrared Imager Radiometer Suite (VIIRS)-based nighttime light (NTL) data for robust extraction and mapping of urban built-up areas [6]. Dou, Liu, He and Hue used VIIRS data for urban land extraction [7].

In this paper a detailed statistical analysis of dynamics of change in Night Radiance Data RH is done. Real time radiance data is monitored from 2 September 2018, 21:16 hours to 4 September 2018, 1:56 hours. This data is day and night band radiance satellite data. This is a detailed analysis of satellite data monitored for 28 hours. The results obtained here help us to identify underlying trends and patterns in the behaviour of this data. Energy consumption dynamics from renewable and non renewable sources used in night light illumination can be explained with these behaviours. The results obtained here can be used in analysis of long term time series day and night band radiance data.

The main contributions of this study are as follows: 1) Statistical analysis of behaviour of day and night band radiance real time RH data for a period of 28 hours; 2) Statistical analysis of behaviour of first order difference of this RH data; 3) Regression of first order difference of RH on RH data over 110 time intervals and analysis of behaviour of 110 values of slopes and Intercepts obtained of this 28 hour data.

The research questions of this study are: 1) How does day and night band radiance RH behave over a real time interval of 28 hours? 2) How is it related to its first order difference? 3)What are the underlying trends and patterns in these two variables?

\section{RESEARCH METHOD}

\subsection{Data}

There are 8936 observations on time series of night radiance $\mathrm{RH}$ data measured by variable Radiative Output with unit $\mathrm{W} / \mathrm{m}^{2}$. On different times ranging from 21:16 hours on 2 September 2018 to 1:56 hours on 4 Sptember 2018, there are 122 intervals of values taken by factor time. This satellite data is a product of National Aeronautics and Space Administration (NASA). They provide real-time imagery of our night time world. These imagery products are from the Visible Infrared Imaging Radiometer Suite (VIIRS) night time sensors. They are also called Day/Night Band, or DNB. This paper uses VIIRS DNB radiance data. DNB imagery has wide range of applications. Their primary purpose is to support short term weather predictions and disaster response community [8]. A number of sources contribute to the DNB signal, including city lights, lightning, fishing fleet navigation lights, gas flares, lava flows, and even auroras. When partial to full illumination from the moon is available, reflection of this lunar illumination off of ice, snow, and other highly reflective surfaces enable the study of ocean and terrestrial features.

VIIRS is a scanning radiometer onboard the Suomi National Polar Partnership (SNPP) Satellite. The VIIRS collects visible and infrared imagery and radiometric measurements of land, atmosphere and oceans. It is sensitive to 22 wavelength bands, including a DNB with 750-m resolution. The DNB is sensitive to visible and near-infrared wavelengths ranging from daylight down to low levels of night time radiance. The ability of the DNB to detect the low levels of visible light present at night makes it well suited to studying night lights [4, 9]. VIIRS sensors have higher resolution and detect low light better than older Defence Meteorological Satellite Program Operational Linescan System (DMSP-OLS) system [10, 11]. Letu, Nakajima and Nishio estimated the $\mathrm{Co}_{2}$ emission by power plants using DMSP-OLS of VIIRS data [12].

Rybnikova and Portnov claim that VIIRS data gives more accurate results than DMSP -OLS data when finding correlation between incidence of breast cancer and artificial lights at night [13]. Similarly Shi et al. claim that VIIRS data are better in forecasting total freight traffic for China than DMSP-OLS data [14]. Satellite data can be used to monitor various parameters related to earth's environment. Near real time monitoring of ecosystem using satellite remote sensing was proposed by Verbesselt, Zeileis and Herold [15].

\subsection{Analysis of 28 hours near real time data a. Box plots}

Box plots provide visual summary of data in terms of quartiles and variance. Thus it is more powerful way of data representation than a tabular representation. By the use of boxplots important 
information can be communicated and absorbed in a glance. It uses the median, the approximate quartiles, and the lowest and highest data points to convey the level, spread, and symmetry of a distribution of data values [16]. Boxplots can also visually represent interrelationships between several variables.

\section{b. Simple Linear Regression}

The dynamics of change in response variable $y$ is studied and predicted using single regressor variable $\mathrm{x}$. We assume that each observation y can be described by the model [17].

$y=\beta_{0}+\beta_{1} x+\varepsilon$

Here $\boldsymbol{\beta}_{\mathbf{0}}$ is the intercept

$\beta_{1}$ is the slope

Suppose that we have n pairs of observations say $\left(\boldsymbol{y}_{1}, \boldsymbol{x}_{\mathbf{1}}\right),\left(\boldsymbol{y}_{2}, \boldsymbol{x}_{2}\right) \ldots \ldots \ldots \ldots\left(\boldsymbol{y}_{n}, \boldsymbol{x}_{\boldsymbol{n}}\right)$. Then these data may be used to estimate $\boldsymbol{\beta}_{\mathbf{0}}$ and $\boldsymbol{\beta}_{\mathbf{1}}$. Here $\mathrm{y}$ is the first order difference of night radiance data and $\mathrm{x}$ is the night radiance data.

\section{RESULTS AND ANALYSIS}

The pattern of change in RH night radiance is minutely analysed. These are 8936 observations on Time Series. On different times ranging from 21:16 hours on 2 September 2018 to 1:56 hours on 4 Sptember 2018 , there are 122 values taken by the factor time. The behavior of mean, median, first quartile (Q1) and third quartile (Q3) over 122 values of factor time is refelected in Figure 1. As seen from this figure and from the size of the boxplot, the variance of the average value over the 122 values of time is the higher than the variance of the median and Q1. The behavior of values in 65\% confidence interval of the mean over 122 values of time is reflected in Figure 2. This figure also shows that the variance of the median values is much lower than the variance of the mean values. The aritnmetic mean is very sensitive to extreme observations in contrast to median and quartiles. So the size of the boxplot for sample mean over different values of time is larger than Medain, Q1 and Q3.

The behavior of mean, median, first quartile (Q1) and third quartile (Q3) of first order difference of $\mathrm{Rh}$ values over 122 values of time is shown in Figure 3. The behavior of these sample statistics over arange of $65 \%$ confidence interval is portrayed in Figure 4. The size of the boxplot corresponding to mean and median in Figure 3 and Figure 4 shows that for the first order difference there are very few extereme observations. Hence the size of boxplot is same in Figure 3 and Figure 4. It is seen that the average values of first order difference of night radiance time series data are very closely spread than the average value of night radiance data. The behavior of spread of the night radiance data over the range of 122 values of time factor is refelected in Figure 5. The pattern in the spread of first order difference is exhibited in Figure 6. The size of the boxplot corresponding to standard deviation SD is same with respect night radiance data and first order difference of night radiance data.

This is standard deviation calculated over 122 values of time. The visual display of slope and intercept over 110 values of time is exhibited in Figure 7. This boxplot shows that while regression first order difference of night radiance data on the night radiance data for different values of time, the slope has more variance than intercept. This implies that the intrinsic value of first order difference is concentrated around 0 . But the rate of change in first order difference for a unit change in RH has a larger spread. The probability density of slope and intercept is exhibited in Figure 8 and Figure 9. The probability density of mean radiance over different values of time factor is exhibited in Figure 10. The probability density of mean of first order difference night radiance data is exhibited in Figure 11. The autocorrelation and partial autocorrelation of the night radiance time series data is given in Table 1 . All the values obtained by correlating 8936 values are highly significant. 
Night Radiance RH Time Series Data

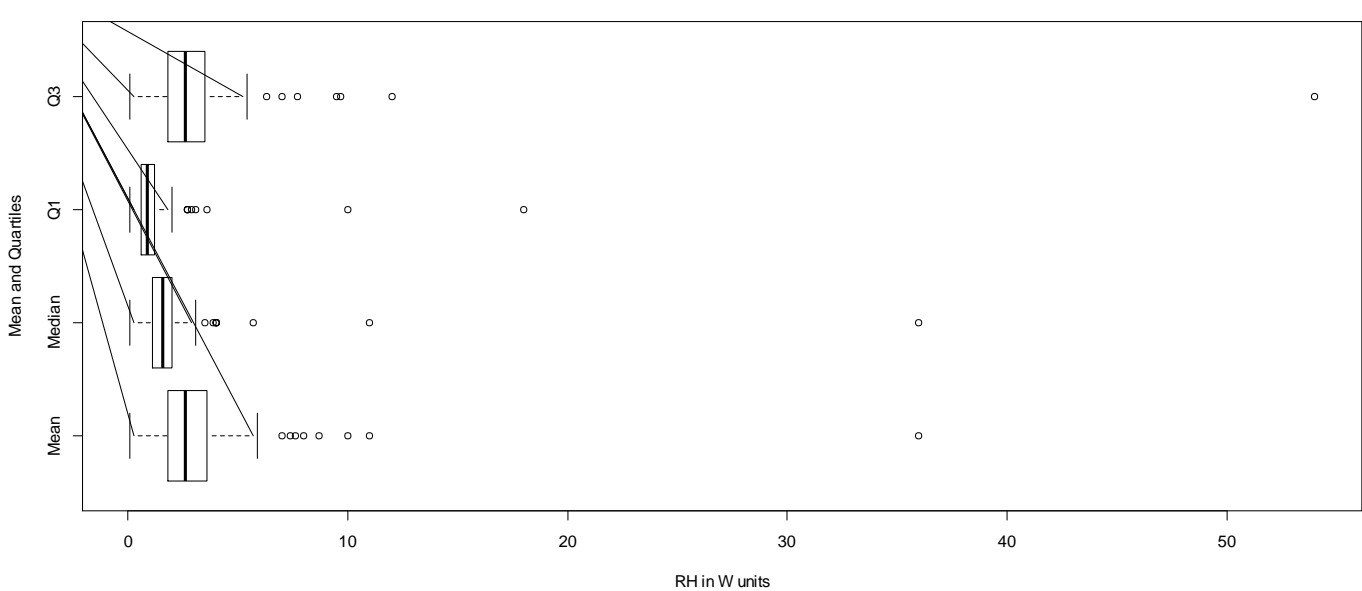

Figure 1. Mean, median, first quartile and third quartile of night radiance over 122 values of time

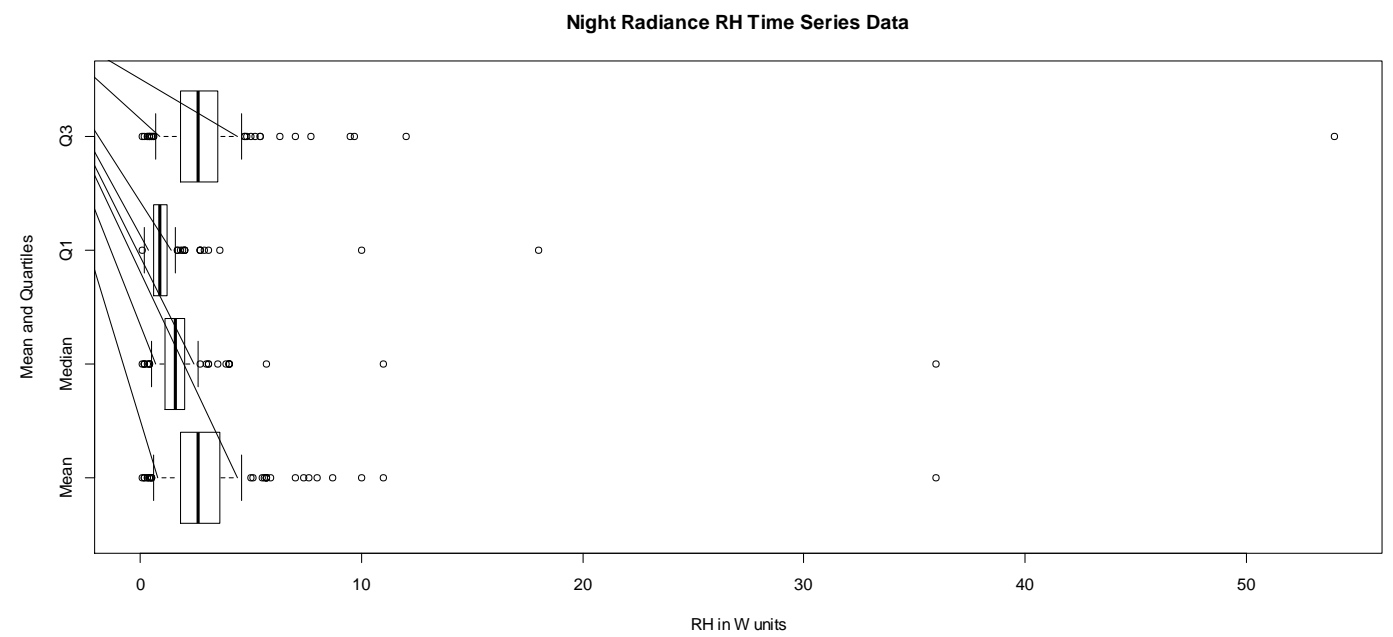

Figure 2. Mean, median, first quartile and third quartile of night radiance over range of $65 \%$ confidence interval

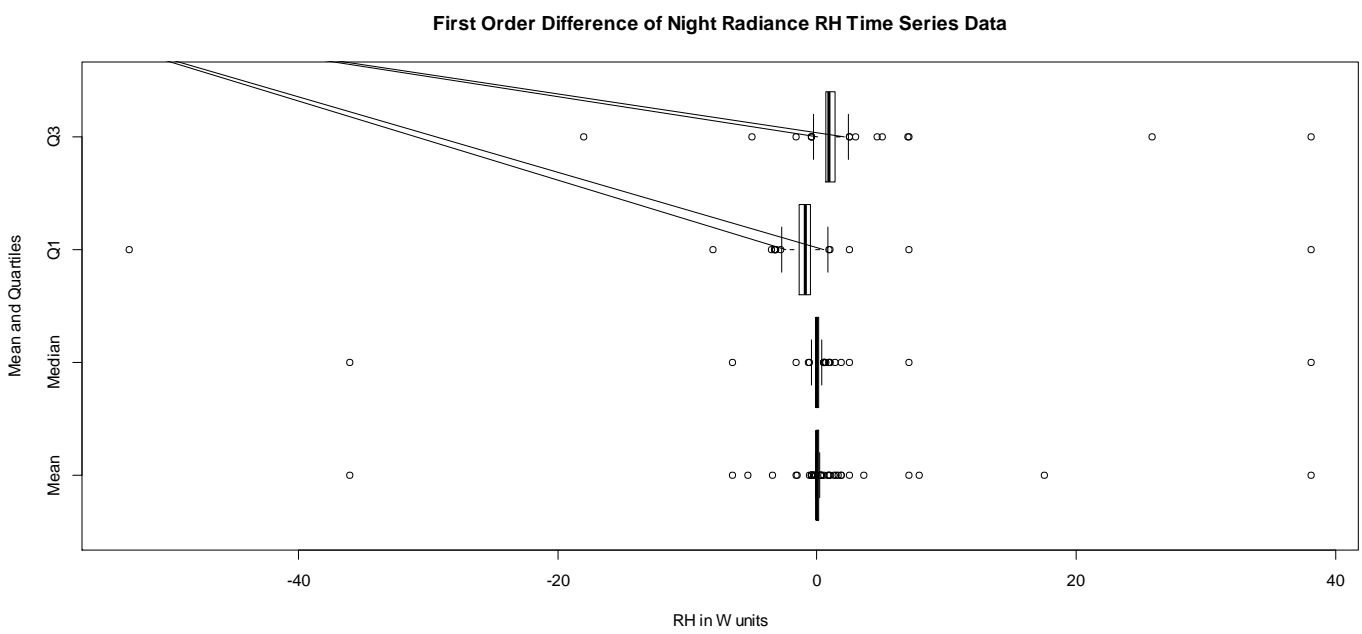

Figure 3. Mean, median, first quartile and third quartile of first order difference night radiance data over 122 values of time 


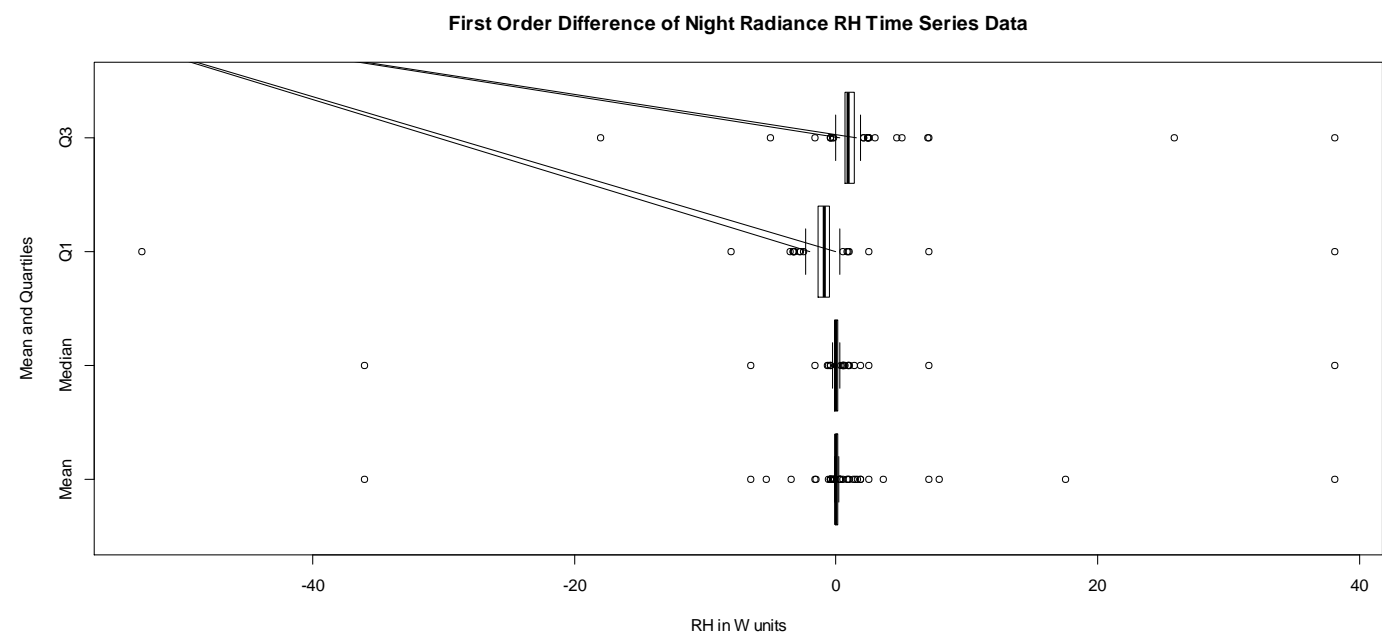

Figure 4. Mean, median, first quartile and third quartile of first order difference night radiance data over range of $65 \%$ confidence interval

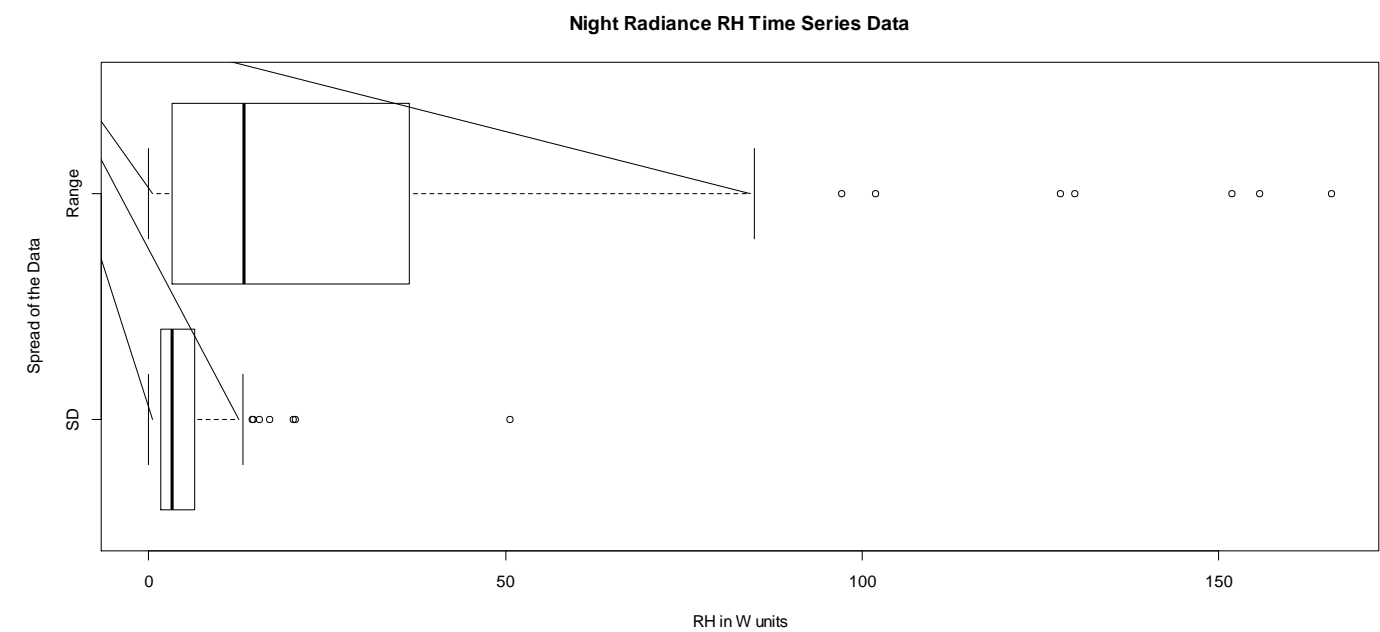

Figure 5. The spread of night radiance RH data in terms of standard deviation and range

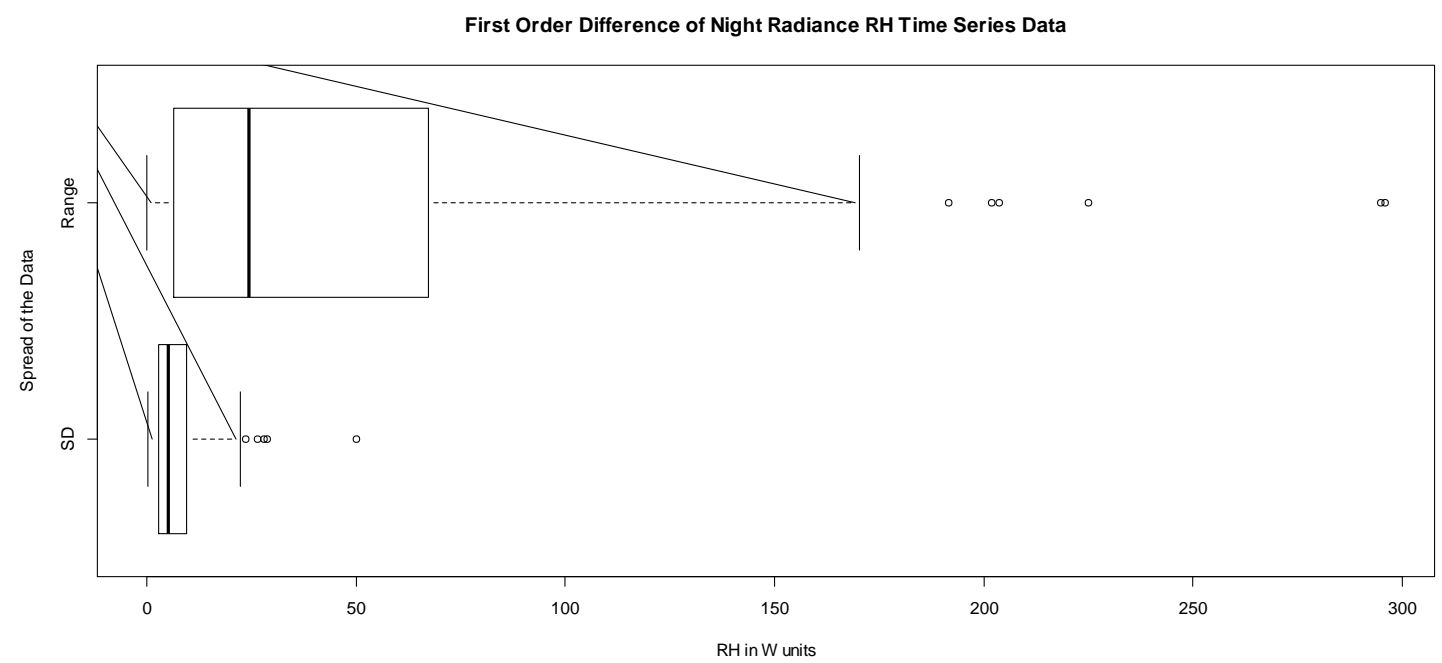

Figure 6. The spread of first order difference of night radiance RH data in terms of standard deviation and range 
First Order Difference of RH regressed on RH

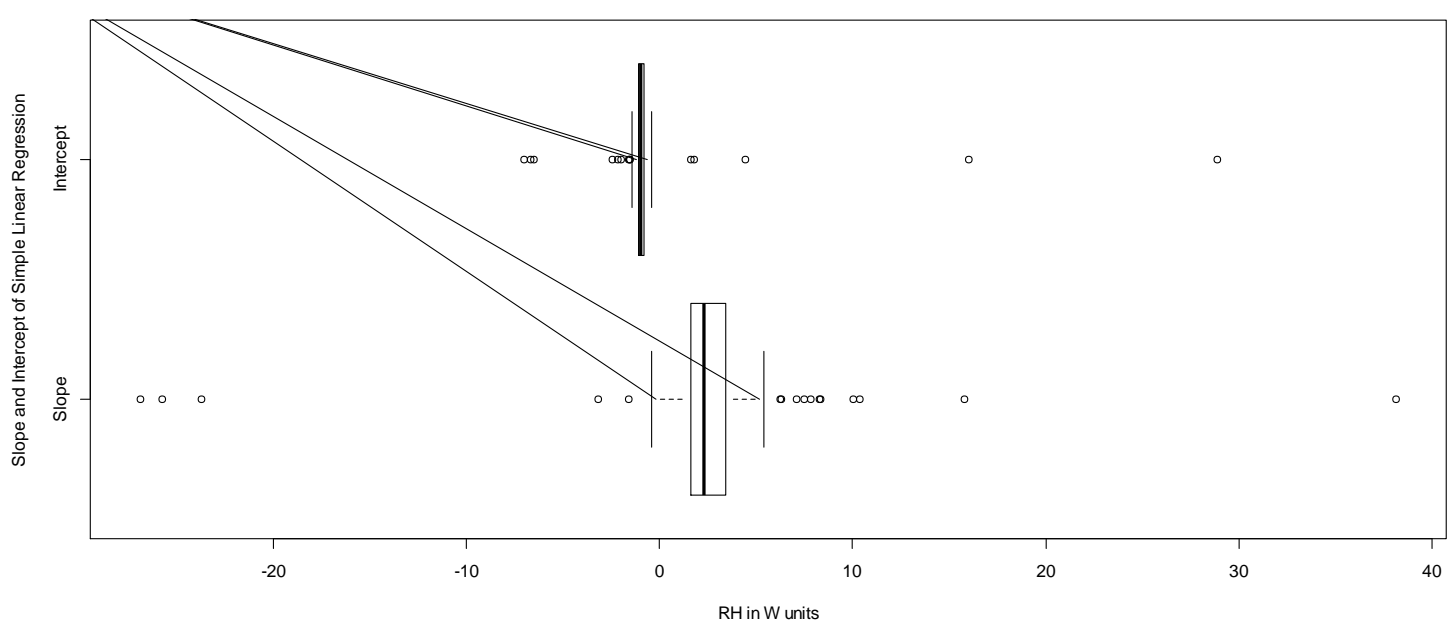

Figure 7. The slope and intercept of linear regressions over 122 values of time

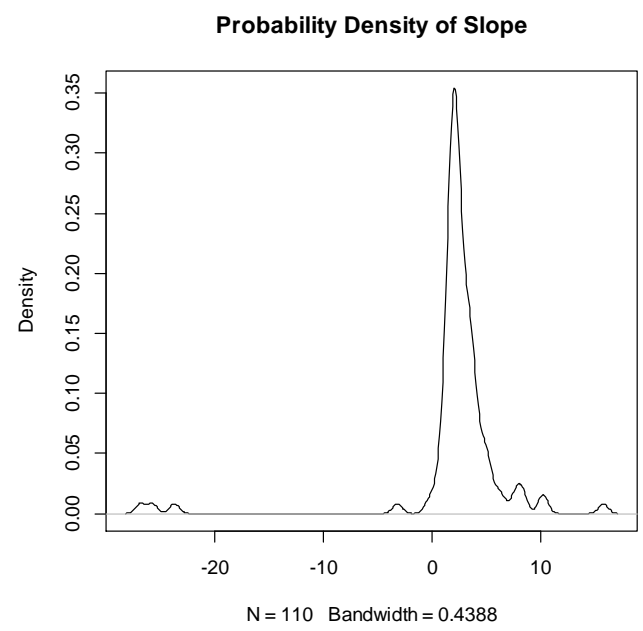

Figure 8 . The probability density of slope over 110 values of time

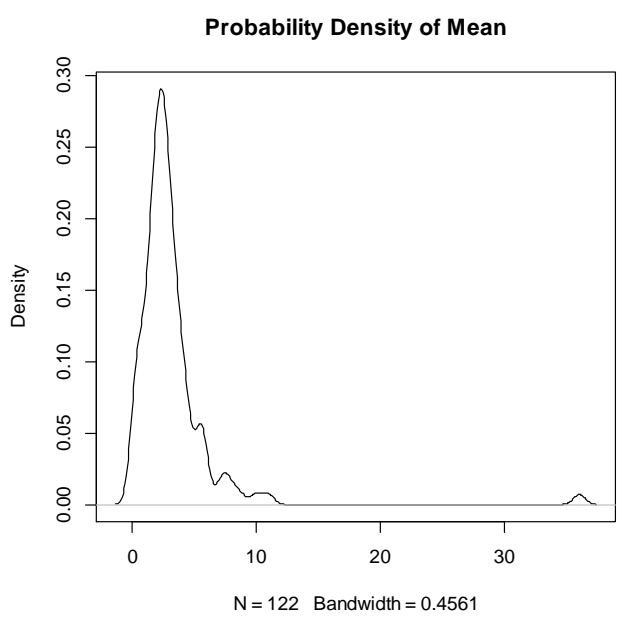

Figure 10 . The probability density of mean radiance over 122 values of time

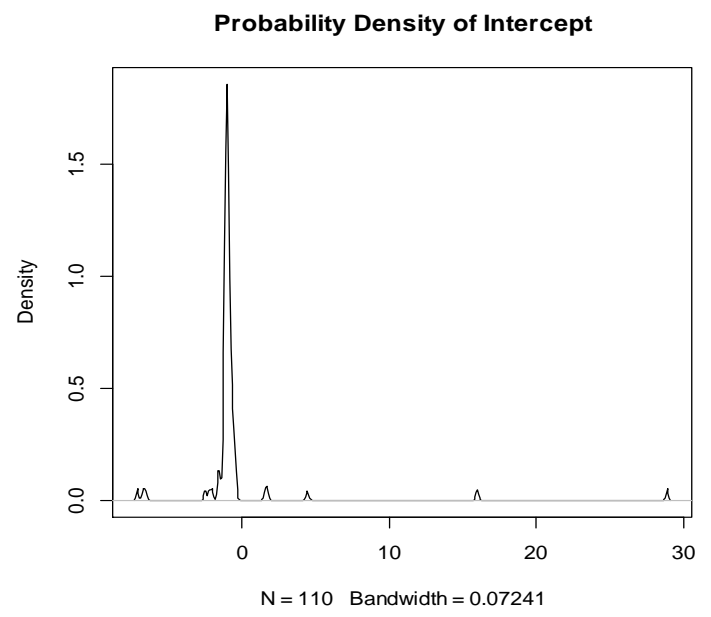

Figure 9. The probability density of intercept over 110 values of time

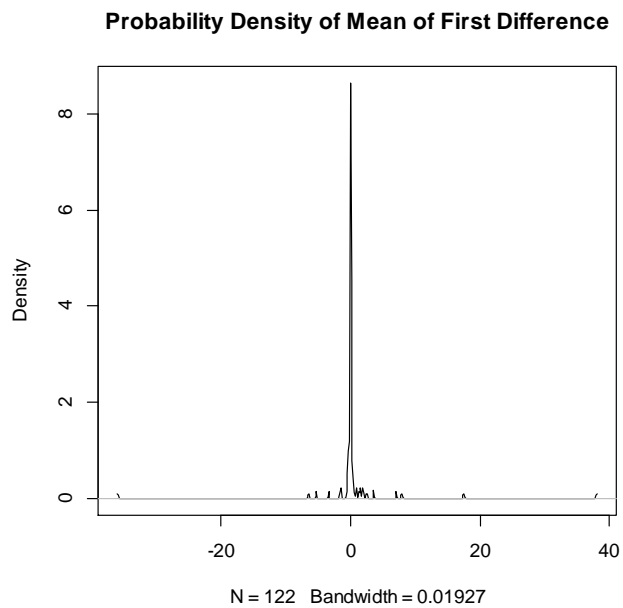

Figure 11. The probability density of mean of first difference radiance over 122 values of time 
Table 1. The Autocorrelation and Partial Auto Correlation of Night Radiance RH Data

\begin{tabular}{cccccccc}
\hline Lag & 1 & 2 & 3 & 4 & 5 & 6 & 7 \\
\hline Autocorrelation & 0.234 & 0.173 & 0.186 & 0.109 & 0.087 & 0.092 & 0.055 \\
Partial Autocorrelation & 0.234 & 0.125 & 0.130 & 0.03 & 0.022 & 0.037 & 0.033 \\
\hline
\end{tabular}

\section{CONCLUSION}

The results obtained in this paper are not means to an end but are complete on its own right. In this paper behaviour of VIIRS day and night band radiance RH is minutely explored. This is based on 28 hour time series data from 2 September 2018 to 4 September 2018. It is seen that the arithmetic mean of night radiance has more spread than the median and the quartiles. This is due to the fact that arithmetic mean is more sensitive to extreme observations. But the mean of first order difference is less sensitive to extreme observations. The size of the box plot of arithmetic means and medians for first order difference are same. This shows that it better to handle first order difference of RH data than the RH data itself. These values have been obtained over 122 values of time. First order difference of night radiance time series data is regressed over the time series night radiance data. The intercept of this simple linear regression conducted on 110 values of time shows the inherent value taken by the first order difference. The slope of this simple linear regression shows the unit change in first order difference of RH over a unit change in the night radiance RH time series data. From the box plot of slope and intercept, it is seen that the spread of intercept is much less than that of slope. This implies that the rate of change in $\mathrm{RH}$ with respect to time has higher variance in comparison to the intrinsic value of RH for the sampled point of time. The probability density of mean of first order difference of RH is symmetric. The autocorrelation of 8936 time series data is highly significant. The partial autocorrelation is also highly significant. The probability distribution of slope and intercept gives an idea on the application of random effects models. These models will be explored in future research.

But this detailed statistical analysis of such data can have vast interdisciplinary applications, especially for countries with limited and scarce data. The effect of night lights is a proxy to electricity consumption; and it permeates into diverse fields ranging from population, disaster management to economics. The intensity of night lights in an area can be taken as an indicator of socioeconomic activities conducted in that area. Such lights are generated by renewable and non renewable energy sources; and they illuminate areas inhabited by human population. Thus night radiance satellite data can be used in analysis of energy consumption dynamics of such areas. The intensity of night lights is highly correlated to the socioeconomic activity conducted in that area. The statistical analysis of night radiance data is related with the statistical analysis of energy consumption.

\section{REFERENCES}

[1] World bank group 2015, Night time lights revisited, Policy Research working paper 7496 (Report)

[2] Christopher D. Elvidge, Mikhail Zhizhin, Feng-Chi Hsu, Kimberly E. Baugh, "VIIRS Nightfire: Satellite Pyrometry at Night", Remote Sens., vol. 5, no. 9, pp. 4423- 4449, 2013.

[3] K. Roychowdhury, S. Jones, "Nexus of Health and Development: Modelling Crude Birth Rate and Maternal Mortality Ratio Using Night time Satellite Images," ISPRS Int. J. Geo-Inf., vol. 3, no. 2, pp. 693-712, 2014.

[4] M. Mann, E. Melas, and A. Malik,"Using VIIRS Day/Night Band to Measure Electricity Supply Reliability Preliminary Results from Maharashtra," Remote Sens., Vol. 8, No. 9, pp. 711, 2016.

[5] B. Yu, K. Shi, Y. Hu, C. Huang, Z. Chen and J. Wu, "Poverty Evaluation Using NPP-VIIRS Nighttime Light Composite Data at the County Level in China," in IEEE Journal of Selected Topics in Applied Earth Observations and Remote Sensing, vol. 8, no. 3, pp. 1217-1229, March 2015.

[6] R. C. Sharma, R. Tateishi, K. Hara, S. Gharechelou \& K. Iizuka, "Global mapping of urban built-up areas of year 2014 by combining MODIS multispectral data with VIIRS nighttime light data," International Journal of Digital Earth, vol. 9, no. 10, pp. 1004-1020, 2016.

[7] Y. Dou, Z. Liu, C. He and H. Yue 2017, "Urban Land Extraction Using VIIRS Night time Light Data: An Evaluation of Three Popular Methods,". Remote Sens, vol. 9, pp. 175, 2017.

[8] Earth Data, https://earthdata.nasa.gov/viirs-dnb

[9] C. Elvidge, M. Zhinzhin, F. Hsu, and K. Baugh, "What is so great about nighttime VIIRS data for the detection and characterization of combustion sources," Proceedings of Asia Pacific Network, vo. 35, pp. 35, 2013.

[10] W. Guo, D. Lu, Y. Wu and J. Zhan, "Mapping Impervious Surface Distribution with Integration of SNPP VIIRS-DNB and MODIS NDVI data," Remote Sens., vol. 7, no. 9, pp. 12459-12477, 2015.

[11] C. D. Elvidge, K. Baugh, M. Zhizhin, F. C. Hsu \& T. Ghosh, "VIIRS night-time lights," International Journal of Remote Sensing, vol. 38, no. 21, pp. 5860-5879, 2017.

[12] H. Letu, T.Y. Nakajima and F. Nishio, "Regional-Scale Estimation of Electric Power and Power Plant CO2Emissions Using Defense Meteorological Satellite Program Operational Linescan System Nighttime Satellite Data," Environ. Sci. Technol. Lett., vol 1, no. 5, pp. 259-265, 2014.

[13] N.A. Rybnikova and B. A. Portnov, "Outdoor light and breast cancer incidence: a comparative analysis of DMSP and VIIRS-DNB satellite data," International Journal of Remote Sensing, vol. 38, no. 21, pp. 5952-5961, 2017. 
[14] K. Shi, B. Yu, Y. Hu, C. Huang, Y. Chen, Y. Huang, Z. Chen \& J. Wu, "Modelling and mapping total freight traffic in China using NPP-VIIRS nighttime light composite data," GIScience \& Remote Sensing, vol. 52, no. 3, pp. 274-289, 2015.

[15] J. Verbesselt, A. Zeileis and M. Herold, "Near real-time disturbance detection using satellite image time series," Remote Sensing of Environment, vol. 123, pp. 98-108, 2012.

[16] D. F. Willaimson, R. A. Parker and J. F. Kendric, "The Box Plot: A Simple Visual Method to Interpret Data," Annals of Internal Medicine, vol. 110, no. 11, pp. 916-921, 1989.

[17] W. Hinnes, D.C. Montgomery, D. M. Goldsman and C. M. Borrer, "Probability and Statistics in Engineering," IV ${ }^{\text {th }}$ edition. John Wiley \& Sons, Inc. 2003, pp. 409-436

\section{BIOGRAPHY OF AUTHOR}

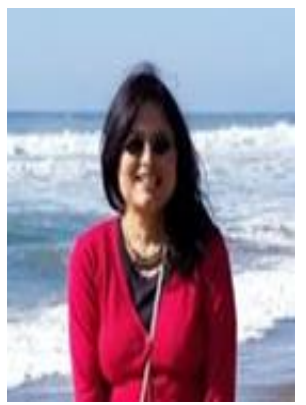

Jyoti U. Devkota, PhD is a Professor of Mathematical Statistics in Kathmandu University, Nepal. Her research interests are interdisciplinary applications of Statistics to problems from Energy and Environment. She focuses on development of new methodologies and application of existing methodologies to data generation, correction, prediction and analysis. She obtained her $\mathrm{PhD}$ degree from Department of Computer Sciences and Mathematics, University of Osnabrueck, Germany, supported by DAAD fellowship. She completed her Masters and Bachelors degree in Mathematical Statistics from Lady Shriram College, University of Delhi, New Delhi, India. 